\title{
OPTIMIZATION OF CALIBRATING HeNe LASER INTERFEROMETERS BY SAMPLE-PERIOD SIMULATION
}

\author{
Lipus, L. C.*; Matus, M.** \& Acko, B.* \\ ${ }^{*}$ University of Maribor, Faculty of Mechanical Engineering, Smetanova 17, SI-2000 Maribor, Slovenia \\ ${ }^{* *}$ Bundesamt für Eich \& Vermessungswesen, A-1160 Vienna, Austria \\ E-Mail: bojan.acko@um.si
}

\begin{abstract}
The calibration procedure for the frequency determination of HeNe laser interferometers used for length metrology is described and high-level traceability at the Metrology Institute of the Republic of Slovenia (MIRS) consistent with the Mutual Recognition Arrangement drawn up by the International Committee for Weights and Measures (CIPM MRA) is presented in the article. The analyses of radiation frequency regarding stabilization time, repeatability and reproducibility are given for a case of an industrial and of a laboratory $\mathrm{HeNe}$ laser interferometer. Allan-deviation calculations at different sampling periods provided information for setting the optimal sampling period and proved that 100000 samples at onesecond or 10000 samples at ten-second long period are usually the most appropriate sets for one-day calibration measurements.

(Received in August 2012, accepted in March 2013. This paper was with the authors 3 months for 2 revisions.)
\end{abstract}

Key Words: Iodine Stabilized Laser, Optical Frequency Standard, Metrological Traceability

\section{INTRODUCTION}

At the time of adoption of the present definition of meter (as the length of the path travelled by light in vacuum during a time interval of $1 / 299792458$ of a second) by the $17^{\text {th }}$ CGPM (General Conference on Weights and Measures, 1983), the International Committee for Weights and Measures (CIPM) drew up recommendations for the practical realization of the definition, called Mise en Pratique (MeP). It was understood that the practical realization would, from time to time, be updated to take account of new measurements and improvements in techniques of laser stabilization.

In 1992, the CIPM decided, on the basis of new work in national laboratories and at the BIPM, to significantly reduce the uncertainties associated with the laser radiations recommended in 1983 and to increase their number from five to eight.

In 1993, the key comparison of International Bureau of Weights and Measures (BIPM.LK10) between national metrology institutes was initiated to provide a basis for demonstrating equivalence of national realizations having taken into consideration only the $633 \mathrm{~nm} \mathrm{HeNe}$ standards: the measurand of the comparison was the difference of the average frequency of the hyperfine components $d, e, f$, and $g$ in the ${ }^{127} \mathrm{I}_{2}, 11-5$ transition, obtained by matrix measurements [1]. During the period 1993 to 1997, the comparisons were performed all over the world. In 1997, the CIPM modified the 1992 instructions by further reducing the uncertainties and increasing the number of recommended radiations from eight to twelve. For HeNe lasers the radiation, stabilized to the $i$-component of the ${ }^{127} \mathrm{I}_{2}, 11-5$ transition, through the third-harmonic detection technique, was $f_{\mathrm{i}}=473612214705 \mathrm{kHz}$ with a relative standard uncertainty of $2.5 \cdot 10^{-11}$ [2]. Further intercomparisons then took place. CIPM key comparisons were statistically analysed on the basis of the ISO Guide by the National Institute of Standards and Technology, USA [3]. 
In the current MeP [4], approved by CIPM (2002), the values are recommended for the $f$ component as follows: Frequency of $f$-component $f_{\mathrm{f}}=473612353604 \mathrm{kHz}$; Relative standard uncertainty of $2.1 \cdot 10^{-11}$; Cold-finger temperature $(15.0 \pm 0.2){ }^{\circ} \mathrm{C}$; Cell-wall temperature $(25 \pm 5){ }^{\circ} \mathrm{C}$; Frequency modulation width $\left.6.0 \pm 0.3\right) \mathrm{MHz}$; One-way intracavity beam power (i.e. the output power divided by the transmittance of the output mirror) $(10 \pm 5)$ $\mathrm{mW}$ for an absolute value of the power shift coefficient $\leq 1.0 \mathrm{kHz} / \mathrm{mW}$. The frequency is about $7 \mathrm{kHz}$ higher than the previous value which is a consequence of absolute frequency measurements performed with optical combs. To ensure that the stated standard uncertainty is achieved at specified operating conditions, appropriate optical and electronic control systems are necessary.

Since the situation for realization of the SI-metre has changed because of the introduction of new techniques for absolute frequency measurements $[5,6]$, it was decided at the $11^{\text {th }}$ meeting of the Consultative Committee for Length (CCL, 2003) at the BIPM to close the K10 comparison and to initiate a new key comparison (BIPM.L-K11), with the expectation that measurements in the pilot and node laboratories be performed by a femtosecond-frequency comb, while measurements in host laboratories may be carried out in either of these ways: as the direct heterodyne measurements between two lasers at the same component (using an acousto-optic modulator for shifting the frequency of one laser, so that the frequency difference can be directly measured), or as matrix heterodyne measurements between two lasers on different components (thus the uncertainty is calculated from several measurements for pairs amongst $d, e, f, g$ components). Subsequently, the CIPM has decided that the combrelated work used to provide external service should stop at the BIPM by the end of 2006; therefore, activity related to BIPM.L-K11 ceased till the end of the year. A proposal for a new scheme for the comparison, based on a group of node-laboratories, piloted by the Bundesamt für Eich- und Vermessungswesen (BEV, Austria) was therefore made. This proposal, which had been approved by the President of the CCL, was given support by the CIPM at its $95^{\text {th }}$ meeting October 2006 and endorsed by the $13^{\text {th }}$ meeting of the CCL in September 2007. This new key comparison, called CCL-K11. The CCL-K11, is designed to provide a technical basis for the review of calibration and measurement capabilities (CMCs) in the field of standard-based optical frequency/wavelength calibration.

The Metrology Institute of the Republic of Slovenia (EURAMET DI: University of Maribor - Faculty of Mechanical Engineering - Laboratory for Production Measurements) joined this on-going key comparison CCL-K11 in the period 2007 to 2009, for the first time, with the laser called MIRS1. The measurement was performed at the pilot laboratory Bundesamt für Eich- und Vermessungswesen (BEV) in Austria with the comb system [7]. The results are in good agreement with MeP [4]. The difference between the predicted and measured frequency was lower than the preliminarily stated standard uncertainty $12 \mathrm{kHz}$ (i.e. the relative standard uncertainty of $2.5 \cdot 10^{-11}$ ), and the uncertainty calculated from the measurements was almost 3-times lower than the preliminarily stated [8]. The beat-frequency procedure for calibration of $\mathrm{HeNe}$ laser interferometers with reference on MIRS1 primary standard laser at Laboratory for Production Measurements was evaluated by EURAMET experts and other regional metrology organizations, than the relevant calibration and measurement capabilities of MIRS were included into CMC base at BIPM, 2010.

The frequency calibration of HeNe laser interferometers commonly gives the average frequency with uncertainty calculated as standard deviation, whereas the calibration procedure at Laboratory for Production Measurements is upgraded with a computer program that also calculates Allan deviation, providing additional information regarding the time-varying of the frequency. Here, some results on sample-period simulations are presented. 


\section{THE CALIBRATION PROCEDURE}

The calibration system in the Metrology Institute of the Republic of Slovenia is applied to the frequency/wavelength measurement of $\mathrm{HeNe}$ lasers used for industrial and laboratory interferometers and stability/reproducibility investigation of laser radiation. It was developed by the Institute of Telecommunications and Acoustics, Wroclaw University of Technology [9, 10], which has more than a decade of expertise in the field of laser technology for industrial optical measurements [11-15].

The equipment comprises the following (Fig. 1):

- Lasertex compact iodine stabilized single-mode HeNe laser (LJSC-3-11 model) as a reference laser named MIRS1;

- Thorlabs optical elements (EBS1 50:50 beam splitter, BB1-E02 mirror, WPMH05M-633 half-wave plate and LPVIS050 linear polarizer);

- Lasertex (Allan Variance Meter AVM-01) photodetector-frequency counter (wavelength 600 to $900 \mathrm{~nm}$ and optical signal sensitivity $20 \mu \mathrm{W}$ ) with Freqmeter software program;

- Hameg HMS 1000 spectrum analyzer $(1 \mathrm{GHz} / 3 \mathrm{GHz})$;

- Thorlabs PM30-120 optical power meter and S120B silicon optical head (400 to 1100 $\mathrm{nm}, 50 \mathrm{nW}$ to $50 \mathrm{~mW}$ ).

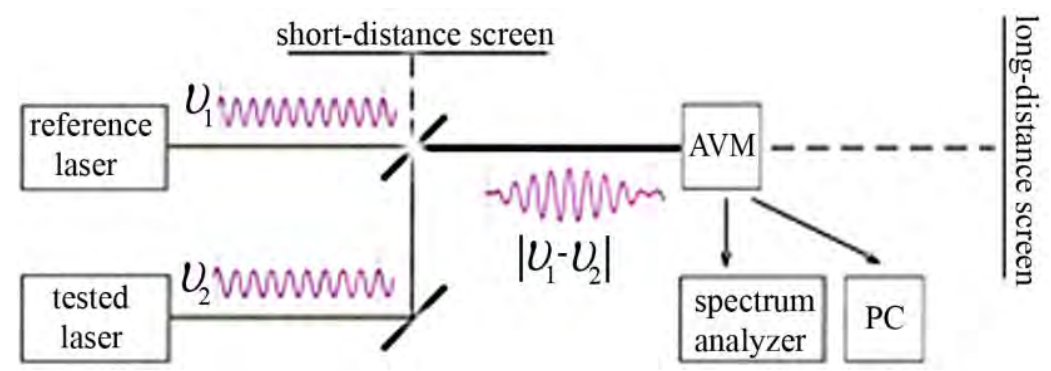

Figure 1: Principle of optical beat measurement.

The reference laser consists of two main parts: a laser head and a controller box. Inside the laser head, the resonator structure is made of a single piece of Invar, and the tube is located between the two mirrors, both attached to piezoelectric transducer actuators, so the cavity length can be adjusted by a voltage supply. The operational principle is to keep the laser wavelength resonant to one of hyper-fine transition of molecular iodine which is accessible with this setup. A Peltier element together with a thermistor is used to keep the cold finger of the iodine cell at a constant temperature of nominally $15^{\circ} \mathrm{C}$. The control electronics of the laser enables not only the use of a programmable procedure for peak detection and adjustment of the control parameters to the changing characteristic of the laser but also the control of the device during operation. The laser wavelength is changed at a constant rate, so the user can observe hyperfine components (Fig. 2) displayed, and lock the chosen frequency $v_{1}$. Starting the laser, the iodine cell temperature is stabilized within 5 to 10 minutes; the temperature of the internal resonator is stabilized within two hours; in normal laboratory conditions the laser is able to keep peaks locked for weeks.

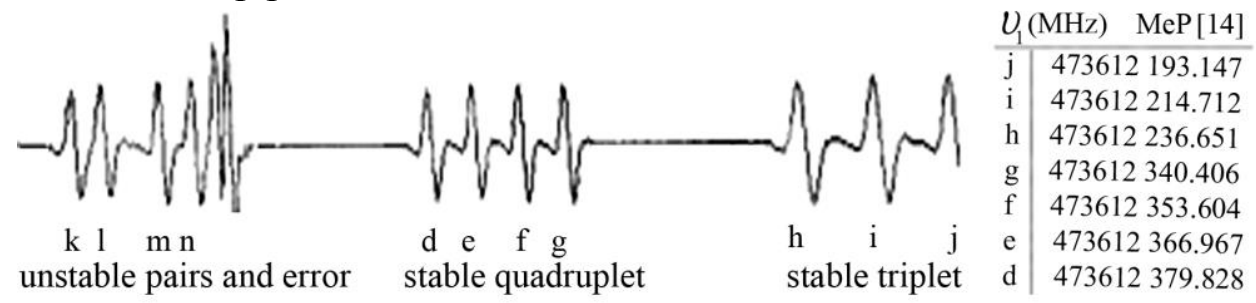

Figure 2: The third harmonic method signal. 
MIRS1 is used as an optical frequency reference for measuring the optical frequencies of laser under test using the beat detection scheme (Fig. 1). The reference beam is directed through the beam splitter to the counter. The beam of the laser under test is directed to the beam splitter and there approximately half of it is reflected toward the optical counter, too. The beams are coaxially aligned on long-distance screen by fine adjustment of the mirrors. The beat frequency of the interfered components is then detected by AVM counter. The alignment geometry should be slightly shifted from the perpendicular position to avoid backreflection from the mirrors into the resonator. Otherwise, the MIRS1 laser is quite insensitive to optical back reflection [15], and with some precaution an optical insulator is not needed.

In this way the polarization directions of both lasers must be the same, otherwise a halfwave plate can be used for selecting one of two components often present in laser interferometers. Usually, the frequencies of horizontal and vertical components differ with a constant in the range 1.5 to $2 \mathrm{MHz}$, but in some exceptions can also be significantly higher.

The optical detector has high optical sensitivity. An optical heterodyne signal generated by mixing the beams, with amplitudes $E_{1}$ and $E_{2}$, is detected by photodiode with electrical output [16]: $\quad I(t) \propto \frac{E_{1}^{2}+E_{2}^{2}}{2}+E_{1} E_{2} \cos \left(2 \pi\left(v_{1}-v_{2}\right) t\right)$

The detector is connected with the spectrum analyzer, used for signal observation and alignment of the detector's lens, and with the computer for precise monitoring of the frequency and stability determination. The signal $\Delta v=\left|v_{1}-v_{2}\right|$ can be preliminarily located by the spectrum analyzer. The chosen peak $v_{1}$ should not be too close to the measured frequency $v_{2}$, otherwise low $\Delta v$ might cross zero, owing to variation of $v_{2}$ and frequency modulation of $v_{1}$. For instance, if a very good interferometer laser has a stability of $2 \cdot 10^{-9}$, then $v_{2}$ may vary $\pm 1 \mathrm{MHz}$; if a good interferometer laser has a stability of $2 \cdot 10^{-8}$, then $v_{2}$ may vary $\pm 10 \mathrm{MHz}$, which is comparable to peak-to-peak differences (Fig. 2).

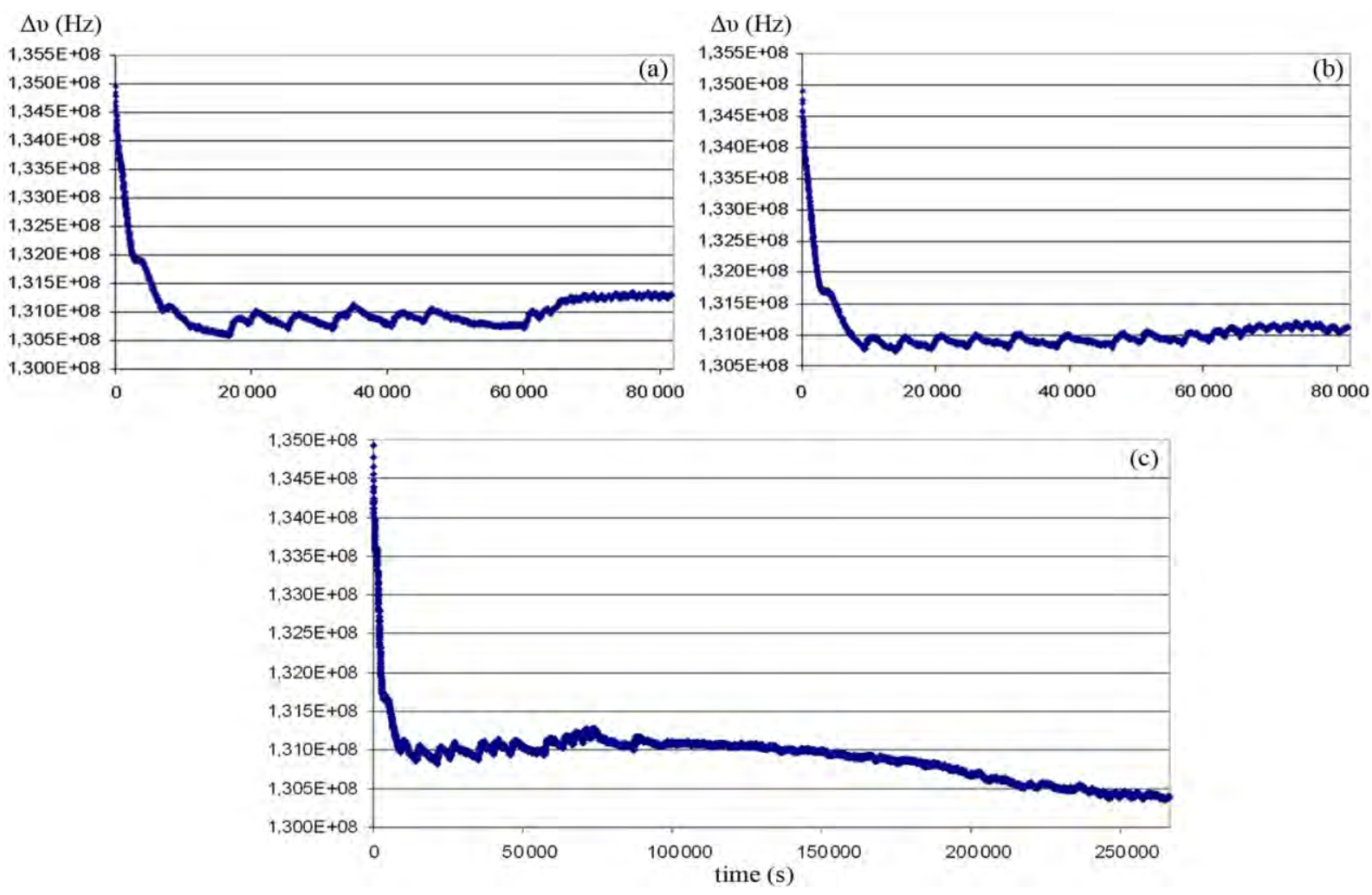

Figure 3: Pulse-frequency plot of laser A (two-hour stabilization time, twenty-hour calibration time), the expanded uncertainty: a) $0.4 \mathrm{MHz}$ during the first day; b) $0.2 \mathrm{MHz}$ during the second day; c) $0.2 \mathrm{MHz}$ during the third day (i.e. the first third of the three-day plot). 
The frequency stability of the HeNe laser interferometer is observed within one-day measurement after initial one- to two-hour warm-up time and the reproducibility of the frequency inside the calibration period is determined after switching off the laser for one hour, and repeating the identical measurement set, at least twice within three days (Figs. 3, 4). The expanded uncertainty is calculated as standard deviation during the calibration period (after the laser was warmed up) for each day and multiplied with 2 for $95 \%$ level of confidence.

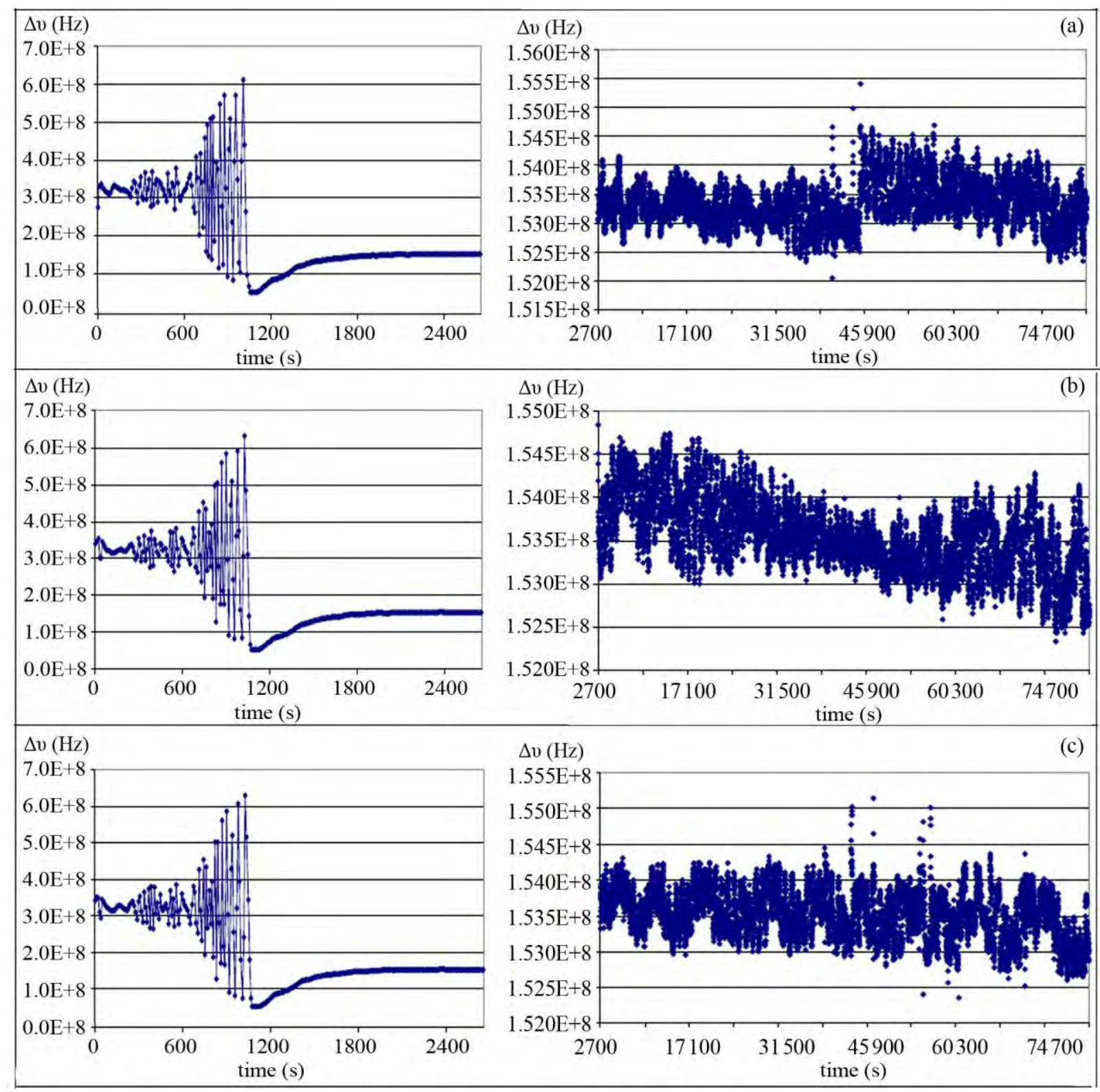

Figure 4: Pulse-frequency plot of laser B (half-hour stabilization time, twenty two-hour calibration time), the expanded uncertainty: a) $0.8 \mathrm{MHz}$ during the first day; b) 0.8 $\mathrm{MHz}$ during the second day; c) $0.7 \mathrm{MHz}$ during the third day.

The measurement at one chosen peak $v_{1}$ yields the information about the absolute difference $\Delta v$ with the possibilities: $v_{2}=\Delta v \pm v_{1}$, therefore, some preliminary observations (with a smaller number of samples) for at least two peaks are needed for final $v_{2}$ determination. To find the correct sign is then quite trivial. 


\section{SAMPLE PERIOD AT THE FREQUENCY MEASUREMENT}

The stability of calibrated HeNe laser interferometers was commonly given with standard uncertainty, whereas the described calibration procedure is upgraded with Freqmeter computer program that enables computation of Allan standard deviation at selected sample period $\tau$. The measured $\Delta v$ is averaged for each $\tau$-long interval $i$. The values $\Delta v_{i}$ depend on duration of the period. When the measurement is completed, the program displays the relative Allan standard deviation $\left(\mathrm{ADEV}_{\mathrm{r}}\right.$, normalized with $\left.v_{1} \approx v_{2} \approx 473612 \mathrm{GHz}\right)$ for the selected mean period $\tau$ :

$$
\operatorname{ADEV}_{\mathrm{r}}=\frac{1}{v_{1}} \sqrt{\frac{\sum_{i=1}^{n}\left(\Delta v_{i+1}(\tau)-\Delta v_{i}(\tau)\right)^{2}}{2(n-1)}}
$$

The program is capable to operate at sample period as low as $0.1 \mathrm{~ms}$, but at very low $\tau$ the stability of the reference laser also influence the results.

Allan standard deviation for MIRS1 was measured at BEV (Fig. 5). In the interval of mean period from 1 to $10 \mathrm{~s}$, it is close to $\mathrm{ADEV}_{\mathrm{r}}$ plot of international reference laser BIPM [6] and of other national metrology institutes, e.g. INMS in Canada [5], the MIKES standard in Finland [16] and the BEV standard in Austria [8], but $\mathrm{ADEV}_{\mathrm{r}}$ of MIRS1 is at $1 \mathrm{~s}$ about 2times higher and at $10 \mathrm{~s}$ about 3-times higher (Table I). Furthermore, it has very specific behaviour in the interval 10 to $100 \mathrm{~s}$, where $A_{D E V}$ increases to a maximum at $50 \mathrm{~s}$. This could be important in the case of calibration of highly stable lab-interferometer lasers; therefore, this critical interval is avoided by setting the Freqmeter on $10 \mathrm{~s}$.

Table I: $\mathrm{ADEV}_{\mathrm{r}}$ of the international and some national standards.

\begin{tabular}{|l|c|c|c|c|}
\hline Sample time & $1 \mathrm{~s}$ & $10 \mathrm{~s}$ & $100 \mathrm{~s}$ & $1000 \mathrm{~s}$ \\
\hline BIPM4 [6] & $7 \cdot 10^{-12}$ & $2 \cdot 10^{-12}$ & $8 \cdot 10^{-13}$ & $1.5 \cdot 10^{-13}$ \\
\hline INMS3 [5] & $7 \cdot 10^{-12}$ & $2.5 \cdot 10^{-12}$ & $7 \cdot 10^{-13}$ & $1.5 \cdot 10^{-13}$ \\
\hline BEV1 [8] & $8 \cdot 10^{-12}$ & $2.5 \cdot 10^{-12}$ & $8 \cdot 10^{-13}$ & $2.5 \cdot 10^{-13}$ \\
\hline MIRS1 [8] & $1.5 \cdot 10^{-11}$ & $6 \cdot 10^{-12}$ & $6 \cdot 10^{-12}$ & $1.3 \cdot 10^{-12}$ \\
\hline
\end{tabular}

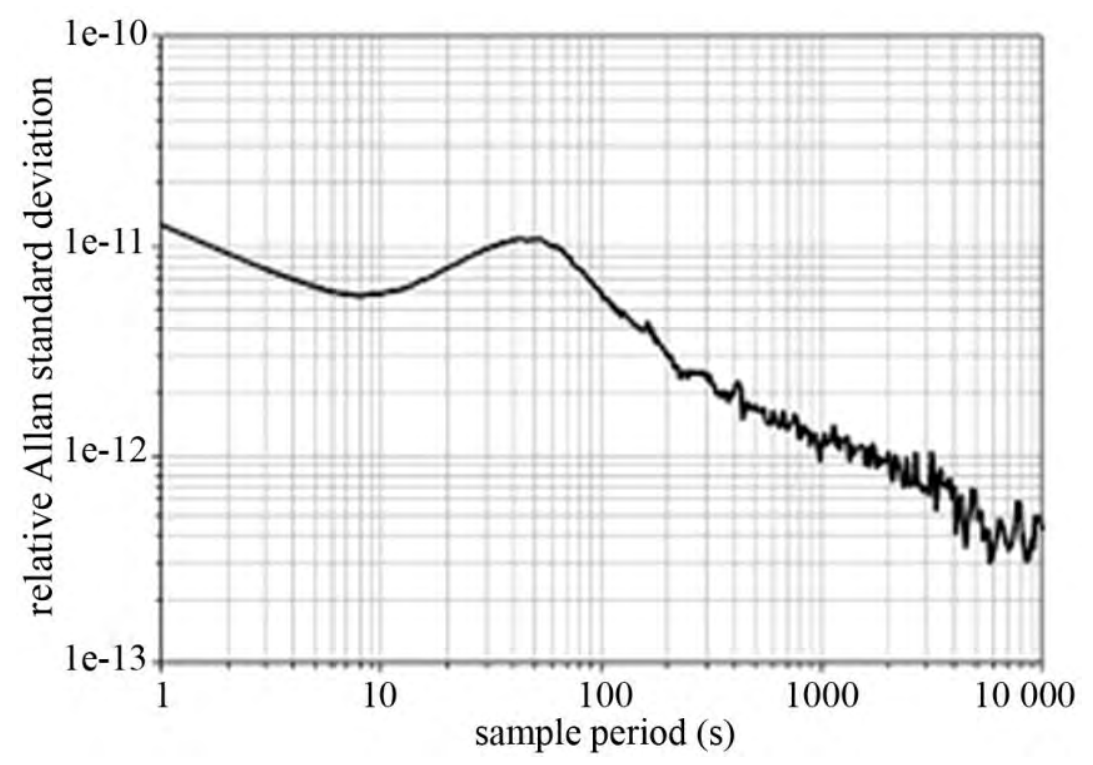

Figure 5: $\mathrm{ADEV}_{\mathrm{r}}$ plot of MIRS1 measured at BEV [8]. 


\section{RESULTS AND DISCUSSION}

Measurements at different sample period $\tau$ gave repeatable diagrams specific for each $\mathrm{HeNe}$ laser interferometer (Fig. 6; (b) plot was produced at the re-calibration two years after the first calibration (a)).

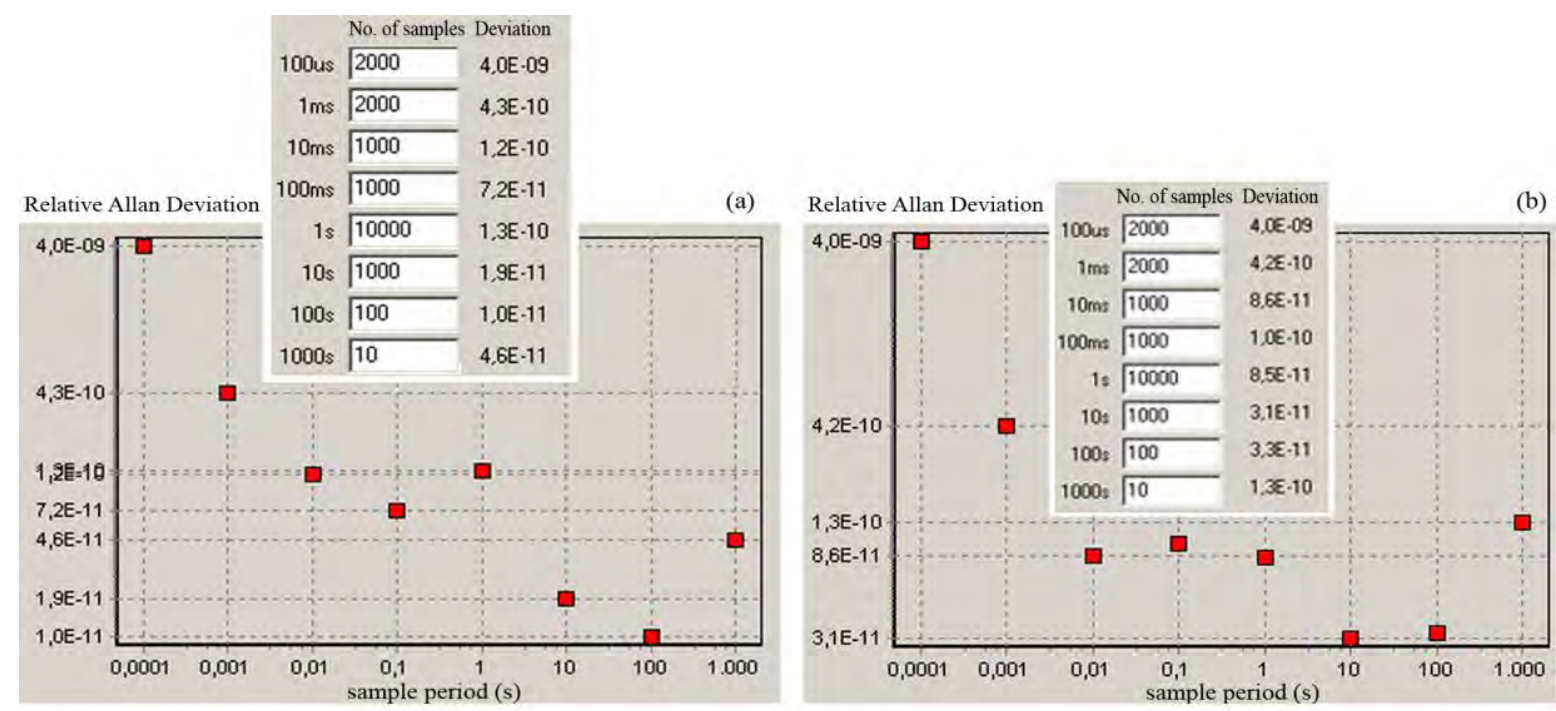

Figure 6: $\mathrm{ADEV}_{\mathrm{r}}$ plot of laser A.
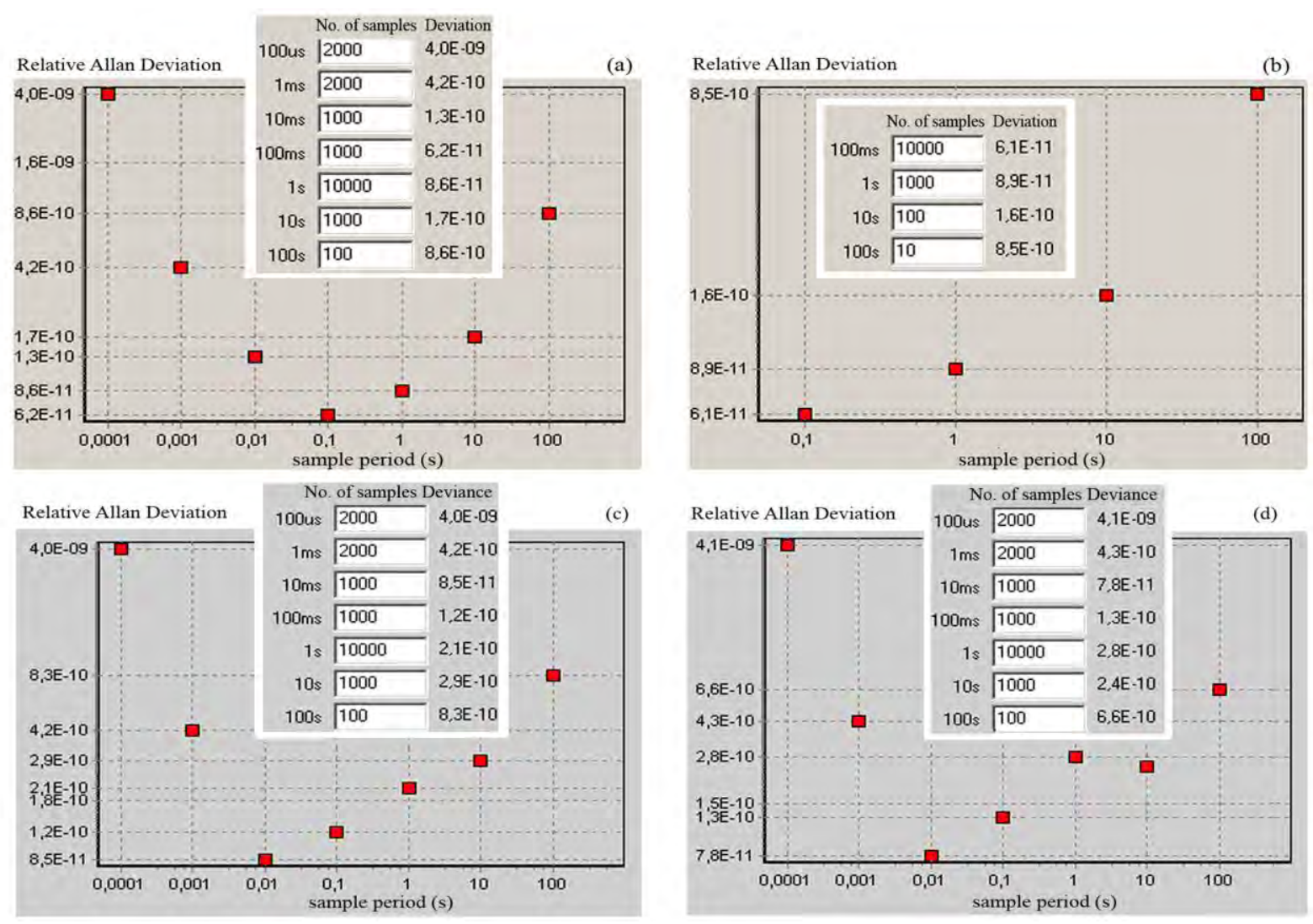

Figure 7: $\mathrm{ADEV}_{\mathrm{r}}$ plot of laser B.

The chosen sample period has greater influence on $A D E V_{r}$ than the number of samples (Fig. 7; plots are produced at the fist calibration (a, b); at re-calibration one year later (c) and 
repeated after two weeks (d)). Regarding the plot minimum correlated with the stability level of HeNe laser interferometer, a calibration set of 100000 samples at $1 \mathrm{~s}$ or 10000 samples at $10 \mathrm{~s}$ is the most appropriate to determinate the frequency value and its stability.

The calibration procedure, described here, is capable to determine the frequency stability of the industrial interferometer lasers with accuracy $10^{-9}$, while the interferometry accuracy is much lower than frequency standard stability: secondary standards (with relative uncertainty of approximately $1 \cdot 10^{-8}$ ) in the form of two-frequency HeNe lasers are routinely used in heterodyne interferometry to perform precision length, angular, straightness, flatness, and velocity measurements. The interferometry technique is also used in some coordinate measuring machines $(\mathrm{CMMs})$ with a typical relative uncertainty of $1 \cdot 10^{-6}$ : long-distance (over 4 meters) [18], three-dimensional (with relative uncertainty even below $1 \cdot 10^{-6}$ ) [19-22], and large-scale three-dimensional CMM systems (up to $100 \mathrm{~m}^{3}$ with relative uncertainty of $5 \cdot 10^{-6}$ ) [23].

Among environmental, geometric and instrumental errors, the most influential contributor to the uncertainty is temperature. The uncertainty contribution of the dynamic behaviour of the system [24] is considered to be negligible. Wavelength compensation, the material thermal compensation and the dead path correction (the length of the laser beam between the interferometer and retro-reflector, with the machine stage at zero position) are needed for such a level of measurement accuracy. Electronics errors (due to the instrument resolution and errors in measurement acquisition), optics non-linearity (due to semi-perpendicularity between the linearly polarized beams, elliptical polarization of the individual beam, non-ideal performance of the optical components, mechanical misalignment between the laser, polarizing optics and targets) and cosine error (due to misalignment of the laser beam to the mechanical axis of motion) usually have a lower uncertainty contribution than the laser itself [25].

The refractive index of the laser beam is affected by deviations in environmental conditions. A variation in the index of refraction introduces an error in the wavelength and changes the displacement measured. From Edlén's equation it can be calculated that a change of $1{ }^{\circ} \mathrm{C}$ or $380 \mathrm{~Pa}$ would yield an error of approximately one part per million, while the humidity would have to change by almost $100 \%$. Similarly, the material of line scales and gauge blocks respond to temperature change with expansion: a $1{ }^{\circ} \mathrm{C}$ change in steel would introduce an error of approximately ten parts per million in the distance measured, while with precise temperature measurement (with a resolution of $0.01 \mathrm{~K}$ ), this error can be reduced to the level $10^{-7}$ [26-30]. By using air-conditioning to maintain smoke/dust free air under normal conditions $\left(20^{\circ} \mathrm{C}, 101.325 \mathrm{kPa}\right.$ and $50 \%$ humidity), precise sensing of these air parameters, and by automatic wavelength-, dead path- and material-thermal compensation, the overall uncertainty less than $1 \mu \mathrm{m} / \mathrm{m}$ can be attained [25].

\section{CONCLUSION}

The Lasertex digitally controlled iodine stabilized HeNe laser, recently upgraded by Wroclaw University of Technology is relatively cheap and easy to use, comparing to commercially available iodine stabilized lasers, and allows both unattended operation and full supervision of the operation. The main advantages of the upgraded system are increased lock-up time (for many weeks in normal laboratory conditions), significantly reduced sensitivity on external conditions (the improved stabilization system of the internal resonator temperature) and on beam back-reflection; digital control enabling the locking to any of seven stable absorption lines, both manually and automatically, and a portable, very compact construction (without necessity of realigning resonator mirrors after transportation). The parameters and characteristics of the laser are originally adjusted to the MeP recommendations, but for 
research purposes, the control system also allows high modification of operational parameters (e.g. the cold-finger temperature, the cell-wall temperature).

This laser was researched at The Metrology Institute of the Republic of Slovenia for an application as a frequency standard. By participating in the international comparison CCL$\mathrm{K} 11$, it was verified as highly accurate for all applications requiring ultimate frequency stability. The relevant calibration and measurement capabilities are now included in the documentation of the Mutual Recognition Arrangement by the International Committee for Weights and Measures. The calibration procedure is upgraded with Freqmeter computer program that enables computation of Allan standard deviation at selected sample period. Simulation of sample time on different cases proved that a set of 100000 samples at $1 \mathrm{~s}$ period or a set of 10000 samples at $10 \mathrm{~s}$ period is the most appropriate to determine the frequency value and its stability.

\section{ACKNOWLEDGEMENT}

This project was co-financed by the Ministry of Higher Education, Science and Technology Metrology Institute of the Republic of Slovenia (MIRS) within the framework of the contract C3212-10-000072 on performing activities and fulfilling obligations of the holder of the national standard of length.

\section{REFERENCES}

[1] Chartier, J.-M.; Chartier, A. (1997). International comparisons of He-Ne lasers stabilized with ${ }^{127} \mathrm{I}_{2}$ at $\lambda \approx 633 \mathrm{~nm}$ (July 1993 to September 1995) Part I: General, Metrologia, Vol. 34. No. 4, 297-300, doi:10.1088/0026-1394/34/4/1

[2] Quinn, T. J. (1999). Practical realization of the definition of the metre (1997), Metrologia, Vol. 36, No. 3, 211-244, doi:10.1088/0026-1394/36/3/7

[3] Kacker, R. N.; Datla, R. U.; Parr, A. C. (2004). Statistical analysis of CIPM key comparisons based on the ISO Guide, Metrologia, Vol 41, No. 4, 340-352, doi:10.1088/0026-1394/41/4/017

[4] Quinn, T. J. (2003). Practical realization of the definition of the metre, including recommended radiations of other optical frequency standards (2001), Metrologia, Vol. 40, No. 2, 103-133, doi:10.1088/0026-1394/40/2/316

[5] Bernard, J. E.; Madej, A. A.; Siemens, K. J.; Marmet, L. (2001). Absolute frequency measurement of the $\mathrm{HeNe} / \mathrm{I}_{2}$ standard at $633 \mathrm{~nm}$, Optics Communications, Vol. 187, No. 1-3, 211-218, doi:10.1016/S0030-4018(00)01085-3

[6] Ma, L.-S.; Picard, S.; Zucco, M.; Cartier, J.-M.; Robertson, L.; Windeler, R. S. (2004). Direct measurement of the absolute frequency of the international reference laser BIPM4, Metrologia, Vol. 41, No. 1, 65-68, doi:10.1088/0026-1394/41/1/009

[7] Matus, M. (2003). Femtosecond comb generator as the primary length standard in Austria, Proceedings of the $11^{\text {th }}$ International Metrology Congress

[8] Matus, M.; Nyholm, K.; Madej, A. A.; Bernard, J. E.; Walczuk, J.; Lipus, L. C.; Castillo, H. A. M.; Vega, R. P.; Bastida, K. B.; Mingolla, M. G.; Malinovski, I.; Tarelho, L.; Franca, R.; Hamid, R.; Sahin, E.; Katic, M.; Simunovic, V.; Robertsson, L. (2010). The CCL-K11 ongoing key comparison: Final report for period 2007 - 2009, from http://www.bipm.org/utils/common/pdf/ final_reports/L/K11/CCL-K11_07-09.pdf, accessed on 25-07-2012

[9] Pienkowski, J.; Rzepka, J.; Sambor, S. (2002). System for calibration of the frequency stabilized He-Ne laser, Optica Applicata, Vol. 32, No. 1-2, 75-84

[10] Budzyn, G.; Dudzik, G.; Rzepka, J. (2007). Portable digitally controlled iodine stabilized He-Ne laser with very long lock-up time, 2007 ICTON Mediterranean Winter Conference, Sousse, Tunisia, 167-169, doi:10.1109/ICTONMW.2007.4446975

[11] Rzepka, J.; Pienkowski, J.; Pawolka, H. (1997). Two-frequency laser interferometer with phase shift measurement, Optica Applicata, Vol. 27, No. 4, 251-254 
[12] Rzepka, J.; Budzyn, G. (2003). Laser measurement system for machine tools, Optical Measurement Systems for Industrial Inspection III, conference paper, Munich, Germany; Book Series: Proceedings of the Society of Photo-optical Instrumentation Engineers (SPIE) 5144, 840846

[13] Budzyn, G.; Fraczek, E.; Fraczek, W.; Mroczka, J. (2006). Influence of a laser beam's frequency stability on dislocation of vortex points in an optical vortex interferometer, Applied Optics, Vol. 45, No. 17, 3982-3984, doi:10.1364/AO.45.003982

[14] Fraczek, E.; Budzyn, G. (2009). An analysis of an optical vortices interferometer with focused beam, Optica Applicata, Vol. 39, No. 1, 91-99

[15] Budzyn, G.; Rzepka, J. (2008). Back-reflection effects in a frequency-stabilized two-mode He-Ne laser, Optics Communications, Vol. 281, No. 22, 5592-5595, doi:10.1016/j.optcom.2008.07.082

[16] Hussein, H.; Sobee, M. A; Amer, M. (2010). Calibration of a Michelson-type laser wavemeter and evaluation of its accuracy, Optics and Lasers in Engineering, Vol. 48, No. 3, 393-397, doi:10.1016/j.optlaseng.2009.10.002

[17] Merimaa, M.; Nyholm, K.; Vainio, M.; Lassila, A. (2007). Traceability of laser frequency calibrations at MIKES, IEEE Transactions on Instrumentation and Measurement, Vol. 56, No. 2, 500-504, doi:10.1109/TIM.2007.891075

[18] Phillips, S. D.; Sawyer, D.; Borchardt, B.; Ward, D.; Beutel, D. E. (2001). A novel artifact for testing large coordinate measuring machines, Precision Engineering, Vol. 25, No. 1, 29-34, doi:10.1016/S0141-6359(00)00052-0

[19] Kim, S.-W.; Rhee, H.-G.; Chu, J.-Y. (2003). Volumetric phase-measuring interferometer for three-dimensional coordinate metrology, Precision Engineering, Vol. 27, No. 2, 205-215, doi: $10.1016 / \mathrm{S} 0141-6359(02) 00228-3$

[20] Lee, H.-H.; Yang, M.-Y.; Shin, W.-C.; Ro, S.-K.; Park, J.-K. (2011). A compact high-precision optical sensor for three-dimensional tool-origin compensation, International Journal of Precision Engineering and Manufacturing, Vol. 12, No. 3, 543-549, doi:10.1007/s12541-011-0068-x

[21] Brajlih, T.; Tasic, T.; Drstvensek, I.; Valentan, B.; Hadzistevic, M.; Pogacar, V.; Balic, J.; Acko, B. (2011). Possibilities of using three-dimensional optical scanning in complex geometrical inspection, Strojniski vestnik - Journal of Mechanical Engineering, Vol. 57, No. 11, 826-833, doi:10.5545/sv-jme.2010.152

[22] Acko, B. (2007). Calibration of measuring instruments on a coordinate measuring machine, Advances in Production Engineering \& Management, Vol. 2, No. 3, 127-134

[23] Cuypers, W.; Van Gestel; N., Voet, A.; Kruth, J.-P.; Mingneau, J.; Bleys, P. (2009). Optical measurement techniques for mobile and large-scale dimensional metrology, Optics and Lasers in Engineering, Vol. 47, No. 3-4, 292-300, doi:10.1016/j.optlaseng.2008.03.013

[24] Raczynski, S. (2011). Uncertainty, dualism and inverse reachable sets, International Journal of Simulation Modelling, Vol. 10, No. 1, 38-45, doi:10.2507/IJSIMM10(1)4.180

[25] Castro, H. F. F. (2008). Uncertainty analysis of a laser calibration system for evaluating the positioning accuracy of a numerically controlled axis of coordinate measuring machines and machine tools, Precision Engineering, Vol. 32, No. 2, 106-113, doi:10.1016/j.precisioneng. 2007.05.001

[26] Decker, J. E.; Schodel, R.; Bonsch, G. (2004). Considerations for the evaluation of measurement uncertainty in interferometric gauge block calibration applying methods of phase step interferometry, Metrologia, Vol. 41, No. 3, L11-L17, doi:10.1088/0026-1394/41/3/L03

[27] Godina, A.; Acko, B.; Druzovec, M. (2007). New approach to uncertainty evaluation in the calibration of gauge block comparators, Measurement, Vol. 40, No. 6, 607-614, doi:10.1016/j.measurement.2006.09.010

[28] Druzovec, M.; Acko, B.; Godina, A.; Welzer, T. (2008). Simulation of line scale contamination in calibration uncertainty model, International Journal of Simulation Modelling, Vol. 7, No. 3, 113-123, doi:10.2507/IJSIMM07(3)1.095

[29] Medic, S.; Kondic, Z.; Runje, B. (2012). Validation of the realised measurement uncertainty in process of precise line scales calibration, Technical Gazette, Vol. 19, No. 2, 333-339

[30] Godina, A.; Vuherer, T.; Acko, B. (2012). Possibilities for minimizing uncertainty of dissimilar materials gauge blocks calibration by mechanical comparison, Measurement, Vol. 45, No. 3, 517524, doi:10.1016/j.measurement.2011.10.018 